\title{
Flood discharge measurement of a mountain river - Nanshih River in Taiwan
}

\author{
Y.-C. Chen \\ Associate Professor, Department of Civil Engineering, National Taipei University of Technology, Taipei, Taiwan \\ Correspondence to: Y.-C. Chen (yenchen@ntut.edu.tw) \\ Received: 2 October 2012 - Published in Hydrol. Earth Syst. Sci. Discuss.: 8 November 2012 \\ Revised: 22 April 2013 - Accepted: 25 April 2013 - Published: 23 May 2013
}

\begin{abstract}
This study proposes a more efficient method of flood discharge measurement in mountain rivers that accounts for personal safety, accuracy, and reliability. Because it is based on the relationships between mean and maximum velocities and between cross-sectional area and gauge height, the proposed method utilizes a flood discharge measurement system composed of an acoustic Doppler profiler and crane system to measure velocity distributions, crosssectional area, and water depths. The flood discharge measurement system can be used to accurately and quickly measure flood data that is difficult to be collected by the conventional instruments. The measured data is then used to calibrate the parameters of the proposed method for estimating mean velocity and cross-sectional area. Then these observed discharge and gauge height can be used to establish the water stage-discharge rating curve. Therefor continuous and realtime estimations of flood discharge of a mountain river can become possible. The measurement method and system is applied to the Nanshih River at the Lansheng Bridge. Once the method is established, flood discharge of the Nanshih River could be efficiently estimated using maximum velocity and the water stage. Results of measured and estimated discharges of the Nanshih River at the Lansheng Bridge differed only slightly from each other, demonstrating the efficiency and accuracy of the proposed method.
\end{abstract}

\section{Introduction}

Discharge data enable populations to distribute and manage finite water supplies. Effective water management requires accurate discharge measurements. With an average annual precipitation of $2471 \mathrm{~mm}$, Taiwan receives abundant rainfall. However, much of this precipitation comes from heavy downpours during summer thunderstorms and typhoons. Distribution of rainfall is therefore uneven, resulting in less water available for use per capita. As water shortages become increasingly apparent in Taiwan, accurate discharge measurements, particularly of mountain rivers, become crucial.

The sources of many of the world's major rivers are located in mountains. These mountain rivers supply a large share of the world's population with fresh water (Viviroli and Weingartner, 2004). A mountain river that usually has a steep gradient and swift current and flows in a narrow valley is a river located within a mountainous region having a stream gradient greater than or equal to $0.2 \%$ (Jarrett, 1992) along its mountain and flatland stretch. Mountains cover about $27 \%$ of the world's land surface, but only $13 \%$ of mountainous rivers have data (Bandyopadhyay et al., 1997). Although the World Meteorological Organization recommends using high-density instrument networks in mountainous areas, the number of stream-gauging stations is still far lower than the recommended number (WMO, 2006). With a total area of about $36179 \mathrm{~km}^{2}$, two-thirds of Taiwan is covered with forested peaks. Steep mountain terrain above $1000 \mathrm{~m}$ elevation constitutes about $32 \%$ of the island area; hills and terraces between 100 and $1000 \mathrm{~m}$ above sea level make up $31 \%$. However, only a few of gauging stations can be found in Taiwan's mountain area. Data for mountain river discharges is thus insufficient due to lack of funding, limitations of conventional measurement methods and instruments for discharge measurement, difficulties in accessing gauging stations, and harsh environments that hinder discharge measurements. 
Understanding the temporal and spatial variability of mountain river hydrology requires measuring discharge directly, systematically, and periodically. The most popular conventional method (current-meter method) for directly measuring discharge first measures velocities and crosssectional areas. The required velocity measurements are obtained by placing a current meter at a desired location. The observations of velocity depend on the methods for estimating mean velocity of the vertical. Generally those methods include velocity distribution method, 0.6 depth method, 0.2 and 0.8 depth method, six-point method, five-point method and three-point method (Herschy, 2009). In addition to the 0.2 and 0.8 depth method observing velocities in each vertical at 0.2 and 0.8 of the depth below the surface, hydrologists in Taiwan also use the 0.6 depth method in shallow depths. However, during rapid flows associated with floods, submerging a meter in water is almost impossible, even when an adequate sounding weight is utilized. Additionally, riverbed instability due to rapid scouring and deposition during flooding make sounding water depth impossible; thus, measuring a cross-sectional area is extremely difficult. Flow conditions during floods are highly unsteady and water stages and discharges vary considerably. Thus, accurate discharge measurements must be completed quickly. Furthermore, conditions when measuring mountain river discharge during floods are far from ideal, especially as floods often occur during thundershowers and typhoons in Taiwan. Heavy rains and rapid flows, combined with threats to the safety of hydrologists and instruments, add to the difficulties associated with obtaining accurate measurements. Consequently, discharge data for mountain rivers are lacking in Taiwan. Due to these unsuitable conditions, using a velocity meter to measure discharge is difficult. Some new monitoring systems apply fixed side-looking Doppler profilers (H-ADCP) to measure river discharge (Nihei and Kimizu, 2008; Le Coz et al., 2008). However, the water depth of the mountain rivers is usually very shallow. Intense rainfall events are frequent enough to cause significant high concentrations of suspended sediment in rivers that can also limit the function of ADCP. These expensive systems are thus rarely used. However, it is possible to install an H-ADCP at an ideal site to measure high flow. A noncontact method that uses such instruments as a float (ISO, 2007; Rantz, 1982), optical current meter (Bureau of Reclamation, 1997), radar (Costa et al., 2006), and satellites (Alsdorf et al., 2007) for estimating the velocity of water surface may be considered. These instruments are safe and quick enough for estimating river discharge. Estimations of mean velocity and area of cross section are important for the noncontact methods. The mean velocity of a cross section is based on water surface velocity and the reduction coefficient. However, accurate surface velocity is difficult to measure since the velocity of the water surface is normally affected by waves, winds, and weather. The appropriate coefficient is also difficult to be determined. The estimation of cross-sectional area is problematic since the cross-sectional area changes in accordance with water stage and discharge.

Measuring discharge levels using conventional methods and instruments during flooding is frequently impossible and very impractical. Thus, many discharges are determined after floods using indirect methods. Most indirect methods, such as the slope-area method (Chow, 1973), step-backwater method (O'Connor and Webb, 1988), contracted opening method (Benson and Dalrymple, 1967), and flow through culverts (Bodhaine, 1968), assume a steady and uniform flow. Mountainous floods, which typically move along steep river courses with debris, are generally unsteady and vary rapidly. Hence, using indirect methods to calculate estimated discharges frequently results in significant errors with accuracy rates of only $30 \%$ or greater (Bathurst, 1990). However, some rediscovered techniques such as dilution gauging (McGuire et al., 2007) and rising bubble method (Hilgersom and Luxemburg, 2012) can be used to measure discharge indirectly.

An accurate method and reliable equipment are needed to directly measure discharge from mountain rivers during high flows. This study applies an efficient method and flood discharge measuring system that can be used to easily and accurately measure flood discharge of a mountain river in Taiwan. Section 2 describes the measuring system, which is composed of an acoustic Doppler current profiler, heavy sounding weight, wireless data transmission system, and crane for quickly measuring the velocity profile. The measurement method for flood discharge, "the efficient measurement method" that makes use of maximum velocity and gauge height to estimate flood discharge, is developed in Sect. 3. In Sect. 4 , the flood discharge measured by the proposed measurement system is used to illustrate the accuracy and reliability of the measurement method.

\section{Flood discharge measuring system}

The flood discharge measuring system must withstand the worst possible weather conditions and strong currents to observe and provide velocities and cross-sectional information for discharge calculations. Instruments can be selected according to the characteristics of each gauging station. Several different instruments are typically utilized to collect data during high flows. The measurement of swift streams with highly unsteady flow condition by current meter presents some problems such as impossible to sound and meter drift downstream. Therefore it would be better to avoid submerging an instrument in the water during high flow.

Based on Lu's work (Lu et al., 2006), the acoustic Doppler profiler (ADP) is placed in a sounding weight. The height of the sounding weight is less than $0.3 \mathrm{~m}$. When the sounding weight is lowered to the position under the water surface $0.4 \mathrm{~m}$, the sounding weight will be stationary in the water and submerged sufficiently to avoid air entrainment beneath 
the transducer. The advantage of the ADP is that it can immediately obtain velocity distribution and water-depth when the ADP touches water (Chen et al., 2007). When adequate sounding weights are used, the ADP can stably measure velocity distribution in each of the selected verticals from water surface. The key instrument of the flood discharge measuring system is the ADP, which is a 3-axis water current profiler. The resolution of velocity distribution and water depth depend on the frequency of ADP. High frequency pings yield more precise data, but low frequency pings travel further in the water. This requires a compromise between the distance that the profiler can measure and the precision of the measurements. Two ADPs with 3.0 and $1.5 \mathrm{MHz}$ are tested at the beginning of the flood discharge measurement. However the 1.5 MHz ADP cannot be used near the right bank when water is too shallow. A 3.0 MHz ADP gives shorter profiling ranges but better spatial resolution. The water depth of the Nanshih River at the Lansheng Bridge is usually less than $6 \mathrm{~m}$ and the maximum profiling range of a $3.0 \mathrm{MHz}$ ADP is $6 \mathrm{~m}$. Thus a $3.0 \mathrm{MHz}$ ADP, which is suited to the hydrological characteristics of the Nanshih River at the Lansheng Bridge, can collect velocity data.

The US Geological Survey (USGS) has developed acoustic velocity meter systems for river discharge observations since the mid-1980s (Laenen, 1985) and using ADCPs on moving boats for discharge measurements since the early 1990's (Oberg and Mueller, 1994), and recently it has been used in observations (ISO, 2005). The profiling range of an ADP is determined by its acoustic frequency. The performance of an ADP is also affected by sediment concentration, air bubbles, and the hydraulic situation in which it is placed. Hence, an observer must first know the flow condition, concentration of suspended sediment, and water depth to select the appropriate acoustic frequency. Because of these factors affecting ADP, it will usually take more time or another ADP with lower frequency to correct enough data. The ADP measures water velocity using the Doppler shift, which is the shift of sound frequency reflected by a moving object (Brumley et al., 1991). The ADP transmits sound at a fixed frequency and obtains echoes returning from sound scatters in the water. These sound scatters are small particles, such as a suspended load, that reflect sound back to the ADP (Boiten, 2000). The ADP transmits a short pulse to measure relative water speed for many depth cells by range-gating the reflected signal as a velocity distribution on a vertical. It also transmits a series of bottom-track pings to determine water depth. Thus, during floods, an ADP can be placed on the water surface to measure the velocity distribution and water depth on a vertical. Although velocity distribution data can be obtained immediately, there are some areas were data is missing. Blanking distance is the distance the emitted sound travels while internal electronics prepare for data reception and the transducers stop vibrating from the transmission and become quiescent enough to accurately record the backscattered acoustic energy (Mueller et al., 2007). Figure 1 shows transducer

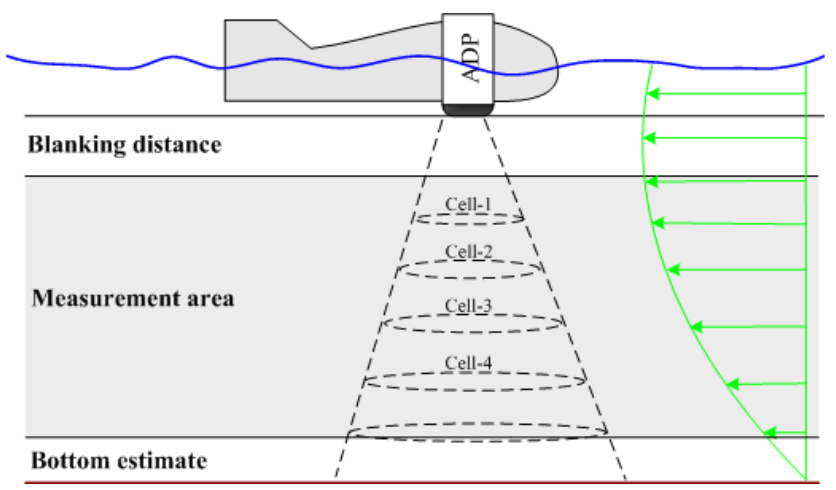

Fig. 1. Unmeasured areas of ADP.

depth, blanking distance, and bottom estimate, respectively. To obtain complete data for the velocity distribution using the ADP, water depth cannot be less than $1.5 \mathrm{~m}$. At such depths, the current meter can be applied to measure the velocity distribution.

The suspended sounding weight is supported by the crane, the ADP is placed inside the sounding weight, and the electronic assembly is placed inside a metal box located above the sounding weight. The velocity distribution can be monitored in real time on a laptop. The electronics assembly supplies power for ADP and processes the signal sent from ADP. To avoid damaging the flood discharge measurement system, application-specific carrying tools and supports are required for the worst conditions. Thus, a $136 \mathrm{~kg} \mathrm{C}$ type sounding weight that is streamlined to offer minimum resistance to flowing water is used as the carrying device for the ADP. This sounding weight stabilizes the ADP and avoids damage from being struck by floating branches, junk and debris. The heavy weight of the sounding weight and ADP makes it impossible to operate without the help of machinery. A mobile crane is used to suspend the measuring system. This crane can be moved quickly among different locations. Because strong currents can overturn sounding weights and destroy the cable between ADP and the laptop, a wireless data transmission system is installed. The signals obtained by ADP are first transmitted through a probe cable to an electronics assembly and then the data is sent to the radio telemetry system to transmit serial data to a wireless processing device - a laptop. The velocity distribution and water depth can be measured instantaneously and then calculated via data analyses. These data can be saved on a computer for further study.

Measurements are usually done from a bridge; the flood discharge measurement is best carried out downstream of the bridge so the sounding weight does not collide with piers. However the discharge measurement is made upstream of the bridge. The reason of discharge measurement upstream of the bridge is that the flow conditions are not affected by piers, less bubbles are found to block the signal, and it is more stable. Additionally, the crane arm must be long enough 
to suspend the sounding weight and position it far away from piers to prevent the sounding weight from colliding with the piers. Therefore the maximum length of the crane arm, which is $10 \mathrm{~m}$, is used when the ADP is applied to measure discharge during typhoons.

\section{Computation of flood discharge}

The discharge equations for open channels are based on the velocity-area method (Herschy, 1999):

$Q=\bar{u} A$,

where $Q$ is discharge; $\bar{u}$ is mean velocity across a channel; and $A$ is the cross-sectional area. Flood discharge measurement of mountain rivers can be estimated directly using mean velocity and cross-sectional area. The estimation of mean velocity is based on the relationship between mean and maximum velocities, and the cross-sectional area can be estimated by gauge height. Therefore estimating mean velocity of the cross section from maximum velocity is unique to the proposed method.

The relationship between mean and maximum velocities (Chiu, 1987) is

$\frac{\bar{u}_{\mathrm{obs}}}{u_{\max }}=\varphi$,

where $u_{\max }$ is the maximum velocity in a channel cross section; $\bar{u}_{\mathrm{obs}}=Q_{\mathrm{obs}} / A_{\mathrm{obs}} ; Q_{\mathrm{obs}}$ is the observed discharge; and $A_{\text {obs }}$ is the observed cross-sectional area. The ratio of $\bar{u}_{\mathrm{obs}}$ to $u_{\max }$ in a given cross section, $\varphi$, approaches a constant (Chiu and Said, 1995; Chiu, 1996). It is a linear relationship passing through the origin. The $\varphi$ ratio characterizes the flow pattern at a given channel cross section, and can be applied to steady or unsteady flows and is unaffected by discharge or the water stage (Chen and Chiu, 2002). Different cross sections of an open channel have different ratios (Chen and Chiu, 2004). Using $\varphi$ ratio to estimate discharge of rivers has been verified in several places including: Taiwan (Chen and Chiu, 2002), US (Chiu and Chen, 2003), Italy (Moramarco et al., 2004), and Algeria (Ammari and Remini, 2010). To determine flood discharge using Eq. (2), one must obtain many sets of $\bar{u}$ and $u_{\max }$ to establish the relationship between maximum and mean velocities - the $\varphi$ ratio. Once $\varphi$ is determined, the flood discharge can be estimated quickly using maximum velocity and gauge height.

\subsection{Estimation of maximum velocity to determine $\varphi$}

To determine maximum velocity, an alternative velocity distribution model is needed that can describe the velocity distribution when maximum velocity is below the water surface. Chiu (1987) derived the following probabilistic velocity distribution equation:

$$
\frac{u}{u_{\max }}=\frac{1}{M} \ln \left[1+\left(e^{M}-1\right) \frac{\xi-\xi_{0}}{\xi_{\max }-\xi_{0}}\right],
$$

where $\xi$ is the isovel in the $\xi-\eta$ coordinate system (Chiu and Chiou, 1988); $u$ is velocity at $\xi ; M$ is the entropy parameter; $\xi_{0}$ and $\xi_{\max }$ are the minimum and maximum values of $\xi$ at which $u=0$ and $u=u_{\max }$, respectively. The y-axis is defined as the vertical on which $u_{\max }$ occurs. One of the advantages of Eq. (3) is that it is capable of describing the velocity distribution whether maximum velocity occurs on or below the water surface. Thus Eq. (3) can be used to determine the maximum velocity from the velocity distribution data measured by ADP, especially maximum velocity occurring under the water surface. Since isovels are intercepted by the y-axis, where both $\xi_{\max }$ and $u_{\max }$ occur, the $\xi$ values of the isovels can be expressed as a function of $y$ on the y-axis:

$\xi=\frac{y}{D-h} \exp \left(1-\frac{y}{D-h}\right)$,

where $D$ is water depth on the y-axis; $y$ is vertical distance from the channel bed; and $h$ is the parameter indicating the location of $u_{\max }$. If $u_{\max }$ occurs on the water surface, $h \leq 0$, and Eq. (3) becomes

$\frac{u}{u_{\max }}=\frac{1}{M} \ln \left[1+\left(e^{M}-1\right) \frac{y}{D} \exp \left(\frac{D-y}{D-h}\right)\right]$.

If $u_{\max }$ occurs below the water surface, $h>0$ and $h$ is the actual depth of $u_{\max }$ below the water surface, and Eq. (3) becomes

$\frac{u}{u_{\max }}=\frac{1}{M} \ln \left[1+\left(e^{M}-1\right) \frac{y}{D-h} \exp \left(1-\frac{y}{D-h}\right)\right]$.

Although the location of $u_{\max }$ in an open channel is not determined easily, it can be obtained using the isovels created with velocity data collected previously. In natural rivers, the y-axis can occur anywhere around the cross section. If the cross section of a relatively straight open channel does not change drastically, the location of the y-axis is extremely steady and does not vary according to changes in time, water level, and discharge (Chiu and Chen, 2003). Restated, the likely location of the y-axis can be identified using historical data, and the maximum velocity of a cross section can be obtained using the y-axis. Statistically, one standard deviation of distance from the y-axis can be used to identify the stability of the y-axis (Chiu and Chen, 1999). The maximum velocity obtained by data from around the y-axis and the actual value are very close; thus, a slight shift in the y-axis will not cause significant error in the estimated maximum velocity (Chiu and Chen, 2003). However ADP cannot sample the velocity near the water surface and channel bed. Hence, the nonlinear regression model can be fitted to velocity distribution data on the $y$-axis measured by the ADP to Eq. (3) for determining maximum velocity in the cross section.

\subsection{Estimation of mean velocity to determine $\varphi$}

The mean velocity of the channel used to establish the relationship between mean and maximum velocities is determined by the ratio of observed discharge and cross-sectional 
area $\left(Q_{\mathrm{obs}} / A_{\mathrm{obs}}\right)$. Thus, measuring flood discharge using the conventional method becomes a very important but difficult task. The conventional method divides the cross section into segments by spacing verticals at an appropriate number of locations across the channel. USGS suggests using 6 to 10 observation verticals in the measurement cross section for a small stream. Reduce the number of sections taken to about $15-18$ during periods of rapidly changing stage on large streams (Rantz, 1982). Distance between verticals, depth, and velocities are measured at the verticals. A sounding weight or ADP is utilized to measure water depths at the verticals. The velocities at the verticals are measured using a current meter or ADP. Segment discharges are computed between successive verticals; therefore, total discharge may be computed as

$$
\begin{aligned}
Q_{\mathrm{obs}} & =\sum q_{i} \\
q_{i} & =\bar{v}_{i} a_{i},
\end{aligned}
$$

where $q_{i}$ is the $i$ th segment discharge; $\bar{v}_{i}$ is the individual segment mean velocity normal to the segment; and $a_{i}$ is the corresponding area of the segment. Notably, $a_{i}$ can be determined using the midsection method.

\subsection{Estimation of cross-sectional area}

The cross-sectional area and gauge height data are collected during discharge measurement. The segment areas are summed to obtain the cross-sectional area of the open channel. If the streambed is stable and free of scouring and deposits, it is normally reliable to estimate cross-sectional area with gauge height. The relationship between cross-sectional area and gauge height (Chen and Chiu, 2002) can be expressed as

$A_{\mathrm{est}}=a(G-b)^{c}$,

where $A_{\text {est }}$ is the estimated cross-sectional area; $G$ is gauge height; and $a, b$, and $c$ are coefficients determined by nonlinear regression. Compared to the cross-sectional area during flood, when the area caused by scouring or depositing is small. Equation (9) can also be applied to estimate crosssectional area. If the relation of $G$ and $A_{\mathrm{obs}}$ is not good enough, it could be a large source of uncertainty in the final discharge.

\subsection{Estimation of the discharge by the efficient measurement method}

Before the discharge estimation method, referred to as the efficient measurement method, is developed in a stream, obtaining $\bar{u}_{\text {obs }}$ to determine $\varphi$ for a given cross section in a stream is key to developing the method. The observed mean velocity of the cross section is calculated as $Q_{\mathrm{obs}} / A_{\mathrm{obs}}$. The complete flood discharge measurements over the full cross section are very important for establishing the relationship

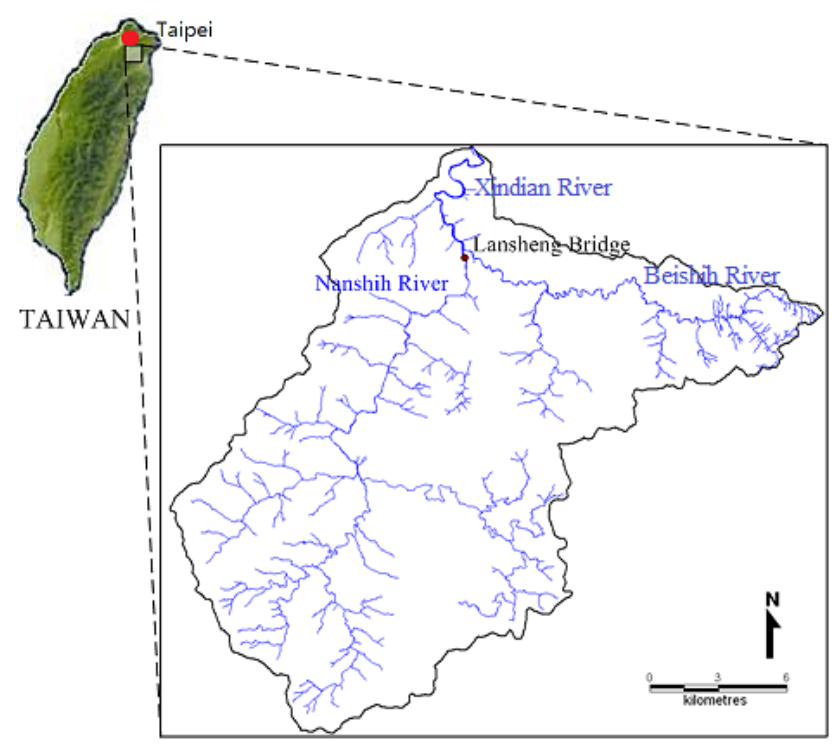

Fig. 2. Location of the study site in the catchment of the Nanshih River, Taiwan.

between mean and maximum velocities and it may possibly take several years to collect enough data. Therefore it is necessary to measure discharge and cross-sectional area by sampling velocities and depth at each vertical for determining mean velocity at each vertical and segment area. Then the discharge is derived from the sum of the product of mean velocity, depth and width between verticals. The velocity distribution made on the $y$-axis is used to calculate maximum velocity of the cross section for determining $\varphi$. The gauge height and cross-sectional area are used to establish the relation of gauge height and cross-sectional area.

Once the method is established, only the velocity distribution on the $y$-axis and gauge height need to be measured for estimating flood discharge. Looking for the location of the $y$-axis in a stream is difficult. For a straight and regular artificial channel, the y-axis usually occurs at the center of the cross section. The location of the y-axis in a natural channel can be located anywhere in the cross section. Fortunately, the velocities used to determine the discharge reveal the location of the y-axis. By using the measured velocity data, isovel patterns of a stream can indicate the location of the y-axis.

The maximum velocity determined by velocity distribution and $\varphi$ can be used to estimate mean velocity of the cross section. The cross-sectional area can be determined by the gauge height. Finally, the flood discharge can be easily estimated by substituting Eqs. (2) and (9) into Eq. (1) to yield

$Q_{\mathrm{est}}=a \varphi u_{\max }(G-b)^{c}$. 


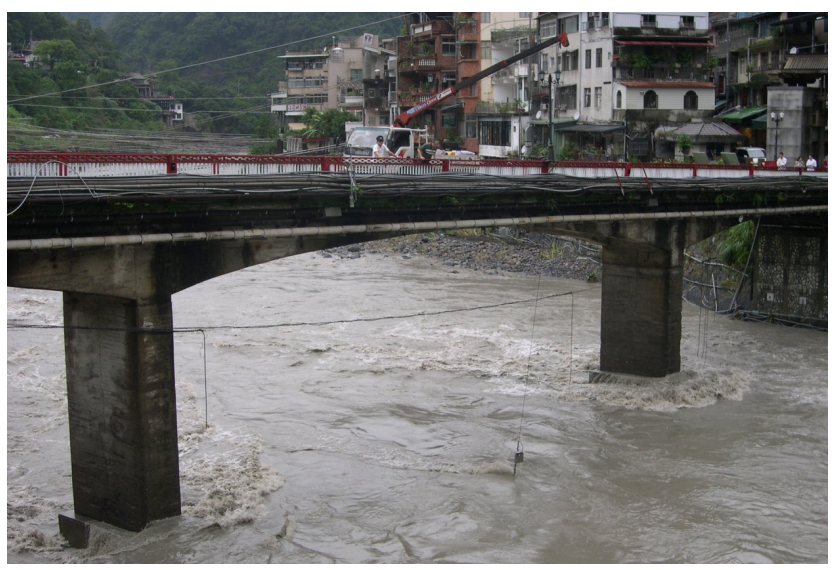

Fig. 3. Flood discharge measurement during Typhoon Krosa.

\section{Description of the study catchment and data}

The study site is located at the Lansheng Bridge on the Nanshih River. Figure 2 shows the locations of the catchment area and gauge stations. Situated southeast of Taipei, Taiwan, the Nanshih River, an upstream branch of the Tanshui River, is a major fresh water source for the Taipei metropolitan area. To safeguard water quality and quantity, access to this area is restricted. Most of the area is thus untouched and forested. The area covers $331.6 \mathrm{~km}^{2}$ and has an annual precipitation of $3082-4308 \mathrm{~mm}$ (average, $3600 \mathrm{~mm}$ ). Days with precipitation are mostly concentrated in winter. The retreating monsoon produces fine rain in winter, whereas typhoons in summer bring heavy rains. The average monthly precipitation in the area from June to October exceeded $300 \mathrm{~mm}$ from 1992. Although a discharge measuring system that is composed of a radar sensor for measuring water stage and current meter for measuring velocity has been in place on the Lansheng Bridge since 2005, flood discharge was not measured until 2007. The average discharge of the Nanshih River at the Lansheng Bridge is $26.9 \mathrm{~m}^{3} \mathrm{~s}^{-1}$; the minimum is $0.9 \mathrm{~m}^{3} \mathrm{~s}^{-1}$, and the maximum is $2295 \mathrm{~m}^{3} \mathrm{~s}^{-1}$. The Nanshih River is about $35 \mathrm{~km}$ long from its source to the Lansheng Bridge and $45 \mathrm{~km}$ to the confluence of the Nanshih River and the Beishih River; its highest altitude is $2101 \mathrm{~m}$ on Mount Babobkoozoo, and the altitude of the river bed at the Lansheng Bridge is $106.8 \mathrm{~m}$. Thus the stream gradient, which is the grade measured by the ratio of drop in elevation of a stream per unit horizontal distance, of the upstream of the Nanshih River exceeds $10 \%$, and the average stream gradient to the Lensheng Bridge is $5.7 \%$. The stream gradient at the study site is about $1.5 \%$, which is still relatively steep.

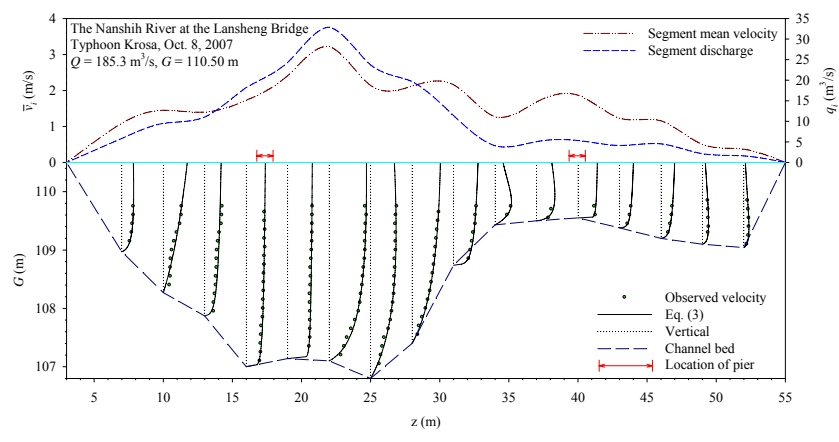

Fig. 4. Depth-velocity graph during Typhoon Krosa (8 October 2007).

\section{Results and discussion}

\subsection{Measurements during flood}

This study was conducted on the Nanshih River at the Lansheng Bridge from 2007 to 2010. During the typhoon season, flood discharges were measured using the proposed flood measurement system. Figure 3 shows the flood discharge measurement during Typhoon Krosa. Since maximum water depth during the non-typhoon season is usually less than $1.5 \mathrm{~m}$, discharge is measured by current meter, not the ADP. At the y-axis $(22 \mathrm{~m}$ from relative point situated at the left bank), velocity measurements are taken at $0.1 \mathrm{~m}$ intervals from the water surface to the channel bed where water is shallow and the ADP cannot be applied to measure velocity distribution.

The velocity distribution and water depth are measured at $3 \mathrm{~m}$ intervals during the typhoons for computation of discharge. The probabilistic velocity distribution equation is then utilized to simulate velocity profiles and calculate the mean velocities of the verticals. Finally, each segmental discharge can be obtained, the sum of which is the river discharge. As shown in Fig. 4, the flood discharge per unit width, mean velocity at each vertical and the corresponding depth are plotted over the water surface line. The top of Fig. 4 is the segmental mean velocity and discharge. The bottom is the flow pattern. It also shows that most of discharge occurs in the main channel. By using the ADP, the crosssection shape can be easily and quickly surveyed for determining cross-sectional area. Table 1 shows the ADP measurements taken during typhoons in 2007 and 2008, of which 8 discharges were measured for five typhoons.

The bottom of Fig. 4 shows the velocity distribution of maximum measured flood discharge in 2007. In Fig. 4, $z$ is the distance from relative point. The discharge was approximately $185.3 \mathrm{~m}^{3} \mathrm{~s}^{-1}$. The dot in Fig. 4 is the actual velocity measurement on each vertical, and the solid line is the velocity distributions based on Eq. (3), indicating that vertical maximum velocity does not always occur on the water surface. Additionally, no definite relationship exists between 
Table 1. Flood discharge measurement of the Nanshih River by using ADP at the Lansheng Bridge in 2007 and 2008.

\begin{tabular}{llrrr}
\hline Typhoon & Date & $G(\mathrm{~m})$ & $A_{\mathrm{obs}}\left(\mathrm{m}^{2}\right)$ & $Q_{\mathrm{obs}}\left(\mathrm{m}^{3} \mathrm{~s}^{-1}\right)$ \\
\hline \multirow{2}{*}{ Sepat } & $9 / 8 / 2007$ & 110.95 & 142.5 & 308.6 \\
& & 110.77 & 119.0 & 266.2 \\
Wipha & $9 / 19 / 2007$ & 110.31 & 91.7 & 171.9 \\
& $10 / 7 / 2007$ & 111.57 & 169.2 & 447.6 \\
Krosa & $10 / 8 / 2007$ & 110.50 & 101.3 & 185.3 \\
& $11 / 28 / 2007$ & 110.45 & 118.8 & 193.6 \\
Mitag & $11 / 29 / 2007$ & 109.88 & 86.6 & 136.8 \\
\multirow{2}{*}{ Sinlaku } & $9 / 15 / 2008$ & 111.52 & 146.9 & 341.1 \\
\hline
\end{tabular}

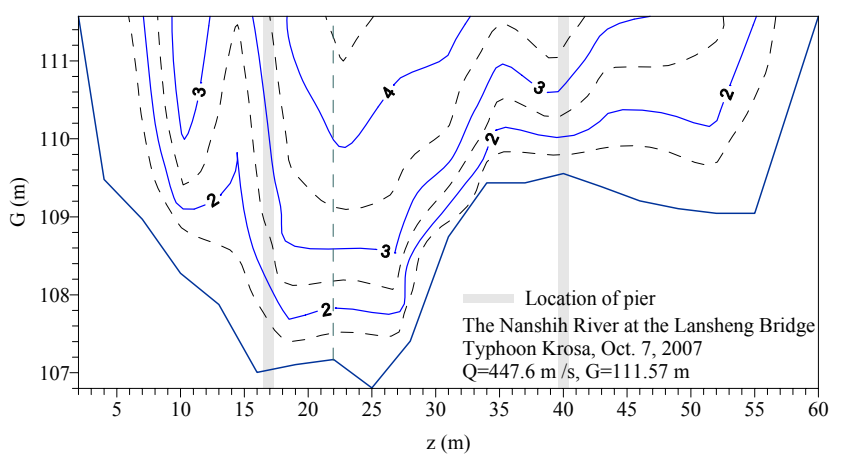

Fig. 5. Isovels in the Nanshih River at the Lansheng Bridge during Typhoon Krosa.

mean and water surface velocity of the river. An accurate measurement of flood discharge must therefore be based on the flow pattern below the water surface and not water surface velocity. However, if the maximum velocity always occurs on the water surface, the relationship between mean and surface velocity can be developed using Eq. (2). The maximum velocity occurred at the vertical, $22 \mathrm{~m}$ away from the relative point. The maximum velocity of the cross section estimated by Eq. (3) was $4.83 \mathrm{~m} \mathrm{~s}^{-1}$ and occurred on the water surface.

Figure 5 shows the isovels based on the observed velocities in Fig. 4. In Fig. 5, the vertical dashed line reveals the location of the y-axis. Owing to the effect of bridge piers, velocities around $z=15 \mathrm{~m}$ and $z=37 \mathrm{~m}$ are lower. Both Figs. 4 and 5 indicate that the major flood discharges are $15-30 \mathrm{~m}$ from the relative point, a sign that velocity on the right bank is slow, and the maximum velocity occurs around the 6th vertical from the left bank and on the water surface. Additionally, the observations of other flow patterns indicate that the maximum velocities always occur on the 6th vertical. This finding suggests that the y-axis is located on the 6th vertical. The y-axis is stable and unaffected by other factors such as stages and discharges.

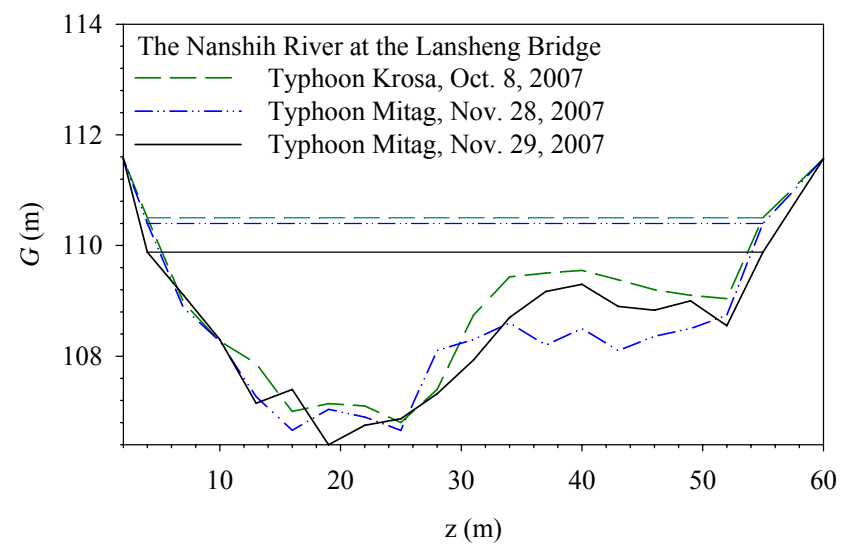

Fig. 6. Scour and deposit of channel bed during Typhoon Mitag.

Table 2. Area variation between two typhoon events.

\begin{tabular}{llrrr}
\hline Typhoon & Date & $G(\mathrm{~m})$ & $A_{v}\left(\mathrm{~m}^{2}\right)$ & $\%$ \\
\hline \multirow{2}{*}{ Sepat } & $9 / 8 / 2007$ & 100.95 & & \\
Wipha & $9 / 19 / 2007$ & 110.77 & 4.1 & 2.9 \\
Krosa & $10 / 7 / 2007$ & 111.57 & -3.4 & -2.9 \\
& $10 / 8 / 2007$ & 111.50 & -0.1 & -0.8 \\
\multirow{2}{*}{ Mitag } & $11 / 28 / 2007$ & 111.45 & -22.5 & -22.2 \\
Sinlaku & $11 / 29 / 2007$ & 109.88 & 6.7 & 5.6 \\
Total & $9 / 15 / 2008$ & 111.52 & 27.0 & 31.2 \\
\hline
\end{tabular}

Figure 6 shows the cross-sectional variation of the channel bed. The main course of the river bed does not change drastically, whereas the right side of the river bed has obvious scouring and deposition during flooding. For instance, on 28 November, the right bank shows obvious signs of scouring, and on 29 November, is deposited; the cross section gradually returns to its previous stage. Based on the cross section on 29 November, the scouring and depositing areas in the cross section on 8 October and 28 November are 13.9 and $7.74 \mathrm{~m}^{2}$, respectively. Table 2 shows the variation of area between two typhoon events. The area varies slightly between Typhoon Sepat and Krosa. At the beginning of Typhoon Mitag, the right side of the river bed is scoured deeply. However, the Nanshih River tends to deposit its sediment at the end of Typhoon Mitag. After scouring and depositing, the change in area is $6.7 \mathrm{~m}^{2}$ between Typhoon Sepat and Typhoon Sinlaku. It shows that the Nanshih River at the Lansheng Bridge is in a state of dynamic stability and near-equilibrium. Compared to the cross-sectional area during flood, the scouring and depositing areas are relatively small. Therefore the observed cross-sectional areas can be used to establish the relation of water stage and crosssectional area. 


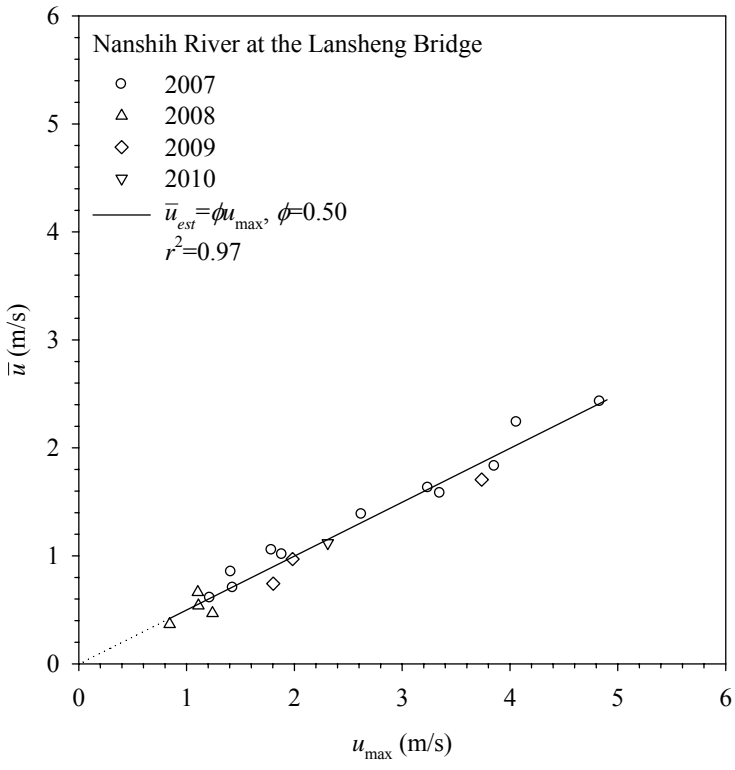

Fig. 7. Relation between mean and maximum velocities.

\subsection{Calibration and validation of the measurement method}

The data of observed discharge is split into two independent subsets: the calibration and validation subsets. The calibration subset with 19 observed discharges is used for parameter estimation. The validation subset, which consists of $5 \mathrm{ob}-$ served discharges, is devoted to access the performance of the proposed method. Correlation coefficients indicating the strength of relationship between observed and estimated discharges and root-mean-square error (RMSE) evaluating the residual of observed and estimated discharges are used to evaluate the performance of the efficient method.

An efficient method of measuring flood discharges of mountain rivers can be established through repeated measurements. Figure 7 shows the relationship between mean and maximum velocities of the Nanshih River at the Lansheng Bridge. It is a straight line that goes through the origin, and $\bar{u}_{\text {est }}=0.5 u_{\max }$. The maximum velocity of the cross section can be calculated by Eq. (4), and the mean velocity is obtained by dividing the measured discharge by the cross-sectional area. All maximum velocities during floods exceed $3 \mathrm{~m} \mathrm{~s}^{-1}$, whereas the $u_{\max }$ on ordinary days can reach $0.8 \mathrm{~m} \mathrm{~s}^{-1}$, indicating a swift current. Moreover, the relationship between mean and maximum velocities is constant and quite stable in a wide range of discharge. It does not vary with time, water stage, or sediment concentration, regardless of whether the flow is steady or unsteady. Using gauge height and cross-sectional area, the relationship between stage and area can be established. It is $A_{\text {est }}=20.51(G-107.57)^{1.53}$, as shown in Fig. 8. Figure 9 shows the accuracy of the crosssectional area estimated by the water stage. The correlation

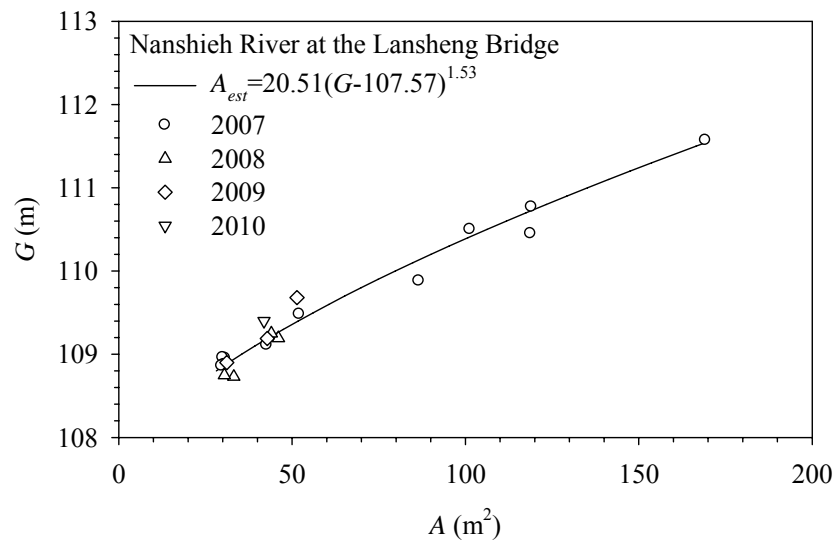

Fig. 8. Relation between gauge height and cross-sectional area.

coefficients in both phases of calibration and validation are very high and RMSEs are low. The estimated areas agree quite well with the observed areas. Therefore, during floods, cross-sectional areas can be estimated based on gauge height.

During flood, maximum velocity can be observed on the $\mathrm{y}$-axis, $22 \mathrm{~m}$ from the relative point. The channel crosssectional area is calculated using gauge height, and mean velocity is obtained using the $\varphi$ value and maximum velocity. Finally, discharge can be estimated by $Q_{\text {est }}=7.34 u_{\max }(G-$ $107.32)^{1.68}$. Figure 10 shows the evaluation of discharge estimation accuracy for the Nanshih River at the Lansheng Bridge. All the data points fall on the line of agreement. The RMSE of the calibration and evaluation are 16.4 and $15.2 \mathrm{~m}^{3} \mathrm{~s}^{-1}$. Moreover, the $\rho$ of the calibration and evaluation are 0.99 and 0.96 , respectively. The results show that the method performance is accurate and consistent in two different subsets. Both correlation coefficients are very close to unity, and both RMSEs are relatively smaller. It demonstrates that the proposed method can be successfully applied to estimate flood discharge of mountain rivers.

\subsection{Uncertainties in the measurement method}

Figure 11 shows the frequency functions for a normal distribution fitted to the $\varepsilon \%$. Figure 11a shows the relative frequency of error percentage. Figure $11 \mathrm{~b}$ shows the cumulative frequency (dots) and probability distribution function (curve). The mean of the errors approaches zero and the absolute measure of error is $7 \%$. Thus the $95.44 \%$ confidence interval for the discharge error is from -2.11 to $2.69 \%$. The $\chi^{2}$ test is employed to determine whether the normal distribution adequately fits data. The $\chi^{2}$ test statistic is $\chi_{c}^{2}=0.57$ and the value of $\chi_{v, 1-\alpha}^{2}$ for a cumulative probability is $\chi_{2,0.95}^{2}=5.99$. Since $\chi_{2,0.95}^{2}>\chi_{c}^{2}$, these errors are mutually independent and normally distributed with a mean approaching zero and small variance. Clearly, the proposed method can be utilized 


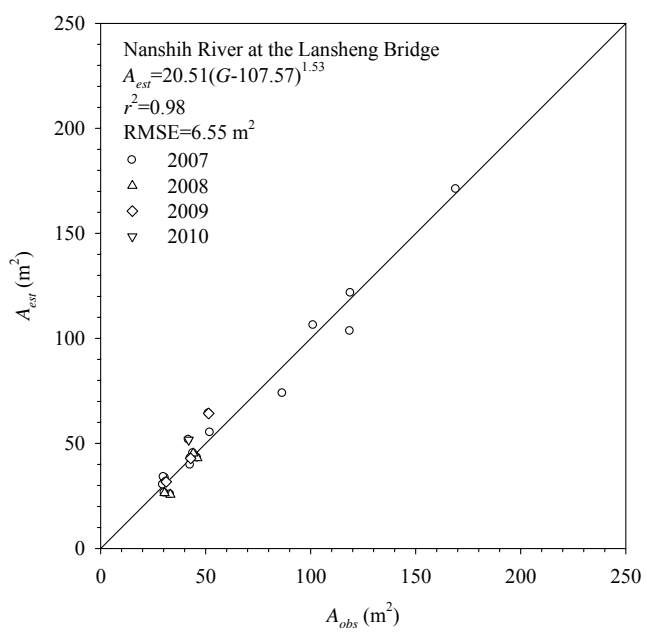

(a)

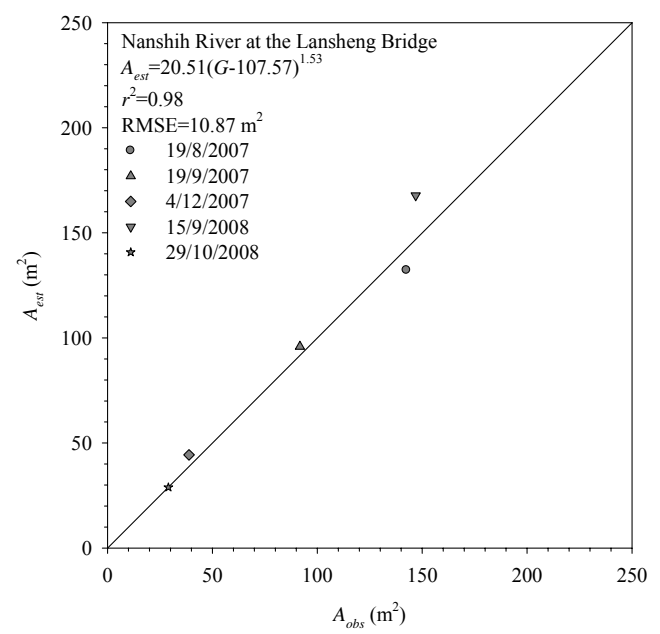

(b)

Fig. 9. Accuracy of estimated cross-sectional area in the Nanshih River at the Lansheng Bridge; (a) calibration; (b) validation.

to accurately and reliably measure flood discharge of mountain rivers.

\subsection{Flood discharge estimated by maximum velocity and water stage}

The gauge station on the Lansheng Bridge was established in 2005 , and it collected discharge data under low water levels by using the current meter method. In 2007, the station began to be used to collect data under high water levels with the method developed in this paper. Once the method for measuring flood discharge of mountain rivers was established, the flood discharges during Typhoon Jangmi in 2008 were estimated only using data on maximum velocities and gauge heights. Figure 12 shows the velocity distribution measured by ADP on y-axis during Typhoon Jangmi. Therefore the maximum velocity can be calculated by using Eq. (3)

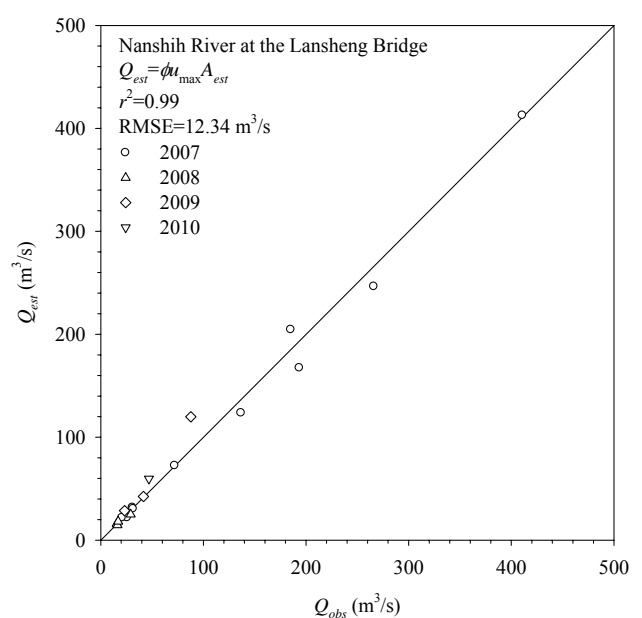

(a)

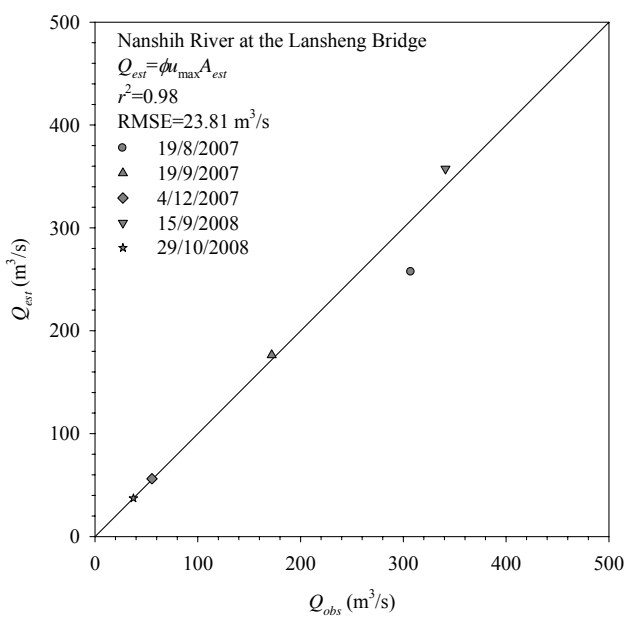

(b)

Fig. 10. Accuracy of estimated discharge in the Nanshih River at the Lansheng Bridge; (a) calibration; (b) validation.

with the collected velocity distribution. The estimated flood discharges during Typhoon Jangmi are summarized in Table 3. In Table 3, $Q$ is discharge estimated by the proposed method, and $Q_{\mathrm{r}}$ is discharge estimated by stage-discharge rating curve. The discharge estimated by only the velocity distribution on the y-axis is very close to the discharge estimated by rating curve. This suggests that the method presented in this paper is accurate and reliable for estimating flood discharge. By using the proposed method, the flood discharge can be estimated quickly within $1 \mathrm{~min}$.

\subsection{Relationship of water stage and discharge}

Real-time discharge at a stream-gauging station can be computed from a real-time stage using the stage-discharge relationship, which is also called the rating curve. Recorded discharges over a wide range are rare. Notably, measurement 
Table 3. Flood discharge of the Nanshih River at the Lansheng Bridge estimated by the efficient method during Typhoon Jangmi on 28 September 2008 (local time, LT).

\begin{tabular}{lrrrrrrr}
\hline $\begin{array}{l}\text { Time } \\
(\mathrm{LT})\end{array}$ & $\begin{array}{r}G \\
(\mathrm{~m})\end{array}$ & $\begin{array}{r}u_{\text {max }} \\
\left(\mathrm{m} \mathrm{s}^{-1}\right)\end{array}$ & $\begin{array}{r}\bar{u}_{\text {est }} \\
\left(\mathrm{m} \mathrm{s}^{-1}\right)\end{array}$ & $\begin{array}{r}A_{\text {est }} \\
\left(\mathrm{m}^{2}\right)\end{array}$ & $\begin{array}{r}Q_{\text {est }} \\
\left(\mathrm{m}^{3} \mathrm{~s}^{-1}\right)\end{array}$ & $\begin{array}{r}Q_{\mathrm{r}} \\
\left(\mathrm{m}^{3} \mathrm{~s}^{-1}\right)\end{array}$ & $\begin{array}{r}Q_{\text {est }}-Q_{\mathrm{r}} \\
\left(\mathrm{m}^{3} \mathrm{~s}^{-1}\right)\end{array}$ \\
\hline $11: 35$ & 112.30 & 4.05 & 2.09 & 213.8 & 448.6 & 496.3 & -47.7 \\
$12: 35$ & 112.20 & 4.51 & 2.33 & 207.8 & 485.4 & 475.9 & 9.5 \\
$14: 05$ & 112.30 & 4.43 & 2.29 & 213.9 & 504.6 & 496.3 & 8.3 \\
$14: 54$ & 112.63 & 4.22 & 2.18 & 233.9 & 511.3 & 566.4 & -55.1 \\
$15: 58$ & 113.18 & 4.93 & 2.55 & 268.0 & 684.4 & 691.6 & -7.2 \\
\hline
\end{tabular}

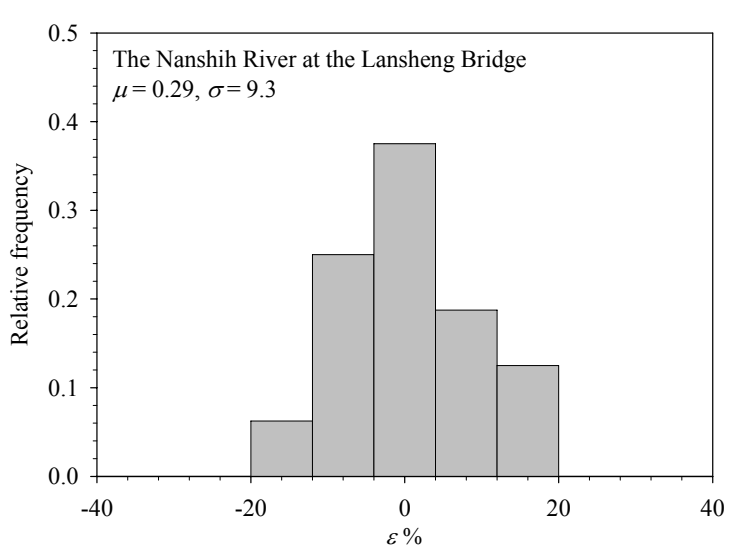

(a)

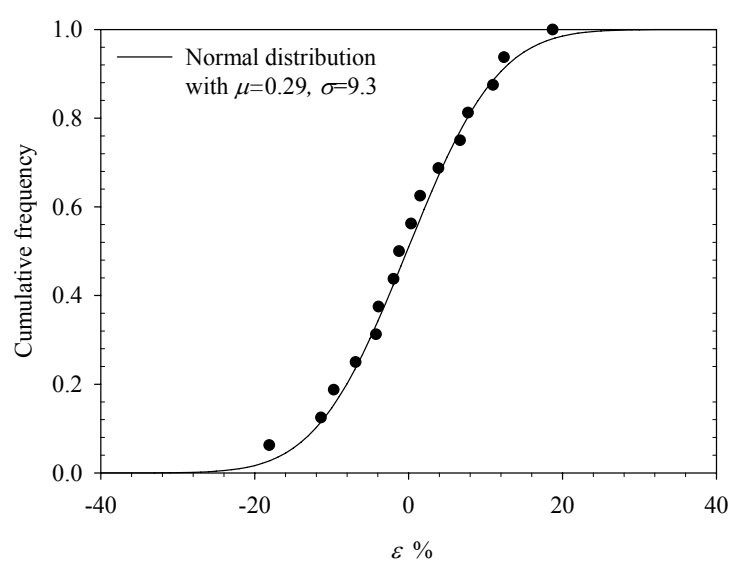

(b)

Fig. 11. Frequency functions for a normal distribution fitted to error \%; (a) relative frequency of error \%; (b) cumulative frequency of error \%.

accuracy of conventional instruments and methods can be adversely affected and restricted by both location and weather; these instruments are most reliable during stable and lowflow conditions. Thus, long-term observations can be used to establish the lower part of a rating curve. However, to create a complete rating curve, high-flow discharge data are needed. Figure 13 is the water-stage rating curve of the Nanshih
River at the Lansheng Bridge. When water stages are 113, 112 , and $111 \mathrm{~m}$, the differences between the discharges estimated by the old and new rating curves are 118, 109, and $81 \mathrm{~m}^{3} \mathrm{~s}^{-1}$, respectively. The old rating curve severely underestimates discharge under high water levels, whereas the curve for 2010 was likely adjusted according to flood discharge, markedly improving its accuracy and efficiency. It indicates the importance of flood discharge for establishing a stage-discharge rating curve. The accurate rating curve with the actual measurements during high water also demonstrates that this method has improved the overall discharge measurement of the river.

By analyzing the data collected from the USGS and Water Resources Agency of Taiwan, my previous works indicate that the method can be used to measure discharge in open channels. In this study, I attempt to organize the measuring system to measure flood data for calibrating all the parameters used in the measurement method. In addition to the method, the measurement system also proves effective for measuring flood discharge. This is the first time that a flood discharge estimate has been based solely on the maximum velocity on the y-axis and the gauge height. Those estimated high flows during typhoons are used to extend the rating curve. Therefore the more accurate flood discharge can be automatically and continuously observed based on the correlation of water stage and discharge.

\section{Conclusions}

Flood discharge measurement is always a difficult and dangerous task. The characteristics of mountain rivers make it impractical to use conventional methods and instruments to measure discharges during floods. To ensure the safety of hydrologists and accurately measure discharge, a new discharge measurement method and system must be developed for flood discharge measurement in Taiwan. Due to the hydrological characteristics of the Nanshih River at the Lansheng Bridge, the flood measuring system was applied to collect velocity and water depth data over the full cross section in order to calculate discharge and determine the location of the y-axis. The efficient discharge measurement method based on the relation of mean and maximum velocities and 

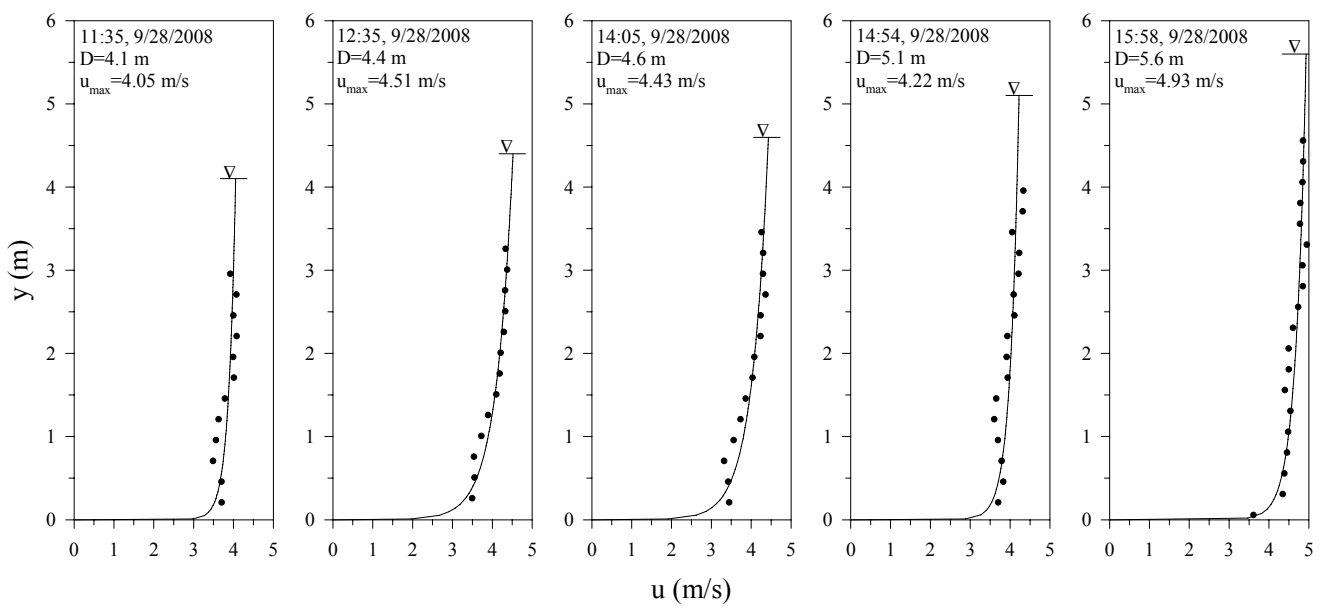

Fig. 12. Velocity distribution on y-axis during Typhoon Jangmi in 2008.

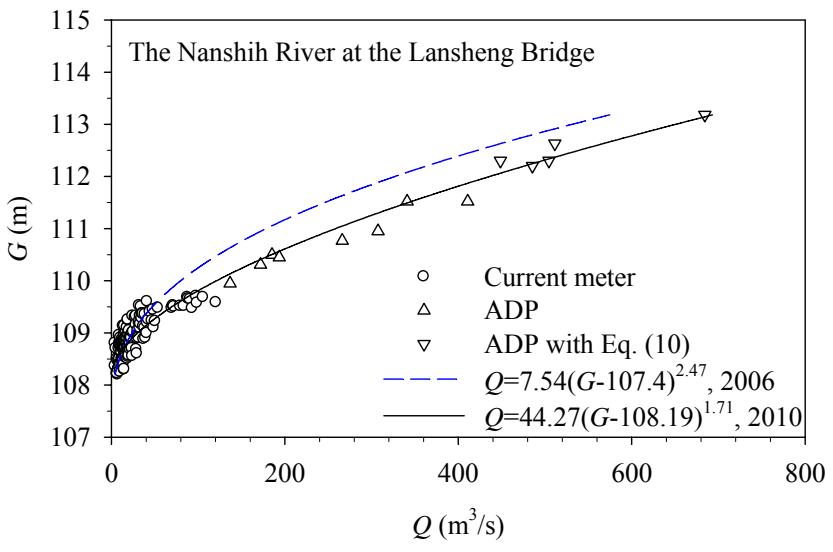

Fig. 13. Stage-discharge rating curve of the Nanshih River at the Lansheng Bridge.

the relation of gauge height and cross-sectional area has been developed to estimate the flood discharge in the Nanshih River at the Lansheng Bridge. Once the parameters of the method are calibrated using the collected flood discharge data, flood discharge can be easily estimated by sampling gauge height and the velocity distribution on the y-axis for calculating maximum velocity. The flood data used for establishing the stage-discharge rating curve makes real time flood discharge estimation possible.

The method is just as effective for measuring flood discharge in mountain rivers as any other index velocity methods that converts the velocity at a point or in a section to the mean velocity. The merits of the proposed measuring system and method for measuring flood discharge of mountain rivers in Taiwan include: (1) considerable accuracy and efficiency; (2) flood discharges can be practically measured - an impossible task previously; and (3) safer conditions for hydrologists, who will not need to be exposed to harsh typhoon and flood environments for prolonged periods. Using the Nanshih River at the Lansheng Bridge, this initial study provides evidence that this method can be effectively applied to flood discharge measurement situations in mountainous areas of Taiwan.

Further studies are needed to demonstrate the efficacy of the measurement method beyond this portion of the Nanshih River. Similar research in other mountain rivers will help to validate the accuracy of the estimates provided by the method. Even though the proposed method is a fast and minimally intrusive measurement method, it is still very dangerous to measure the velocity distribution on the y-axis during floods. It may be practical to also consider developing a model for estimating maximum velocity not on the y-axis.

Acknowledgements. The author is indebted to anonymous reviewers for their valuable comments and suggestions. The author would like to thank the Taipei Water Management Office, Water Resources Agency of Taiwan, for financially supporting this research. Contributions by Profs. J.-T. Kuo and H.-C. Yang are also gratefully acknowledged.

Edited by: M. Mikos

\section{References}

Alsdorf, D. E., Rodríguez, E., and Lettenmaier, D. P.: Measuring surface water from space, Rev. Geophys., 45, RG2002, doi:10.1029/2006RG000197, 2007.

Ammari, A. and Remini, B.: Estimation of Algerian rivers discharges based one Chiu's equation, Arab. J. Geosci., 3, 59-65, 2010.

Bandyopadhyay, J., Rodda, J. C., Kattelmann, R., Kundzewicz, Z. W., and Kraemer, D.: Highland waters - a resource of global significance, in: Mountains of the World: A Global Priority, Parthenon, London, UK, 131-155, 1997. 
Bathurst, J. C.: Tests of three discharge gauging techniques in mountain rivers, in: Hydrology of Mountainous Areas, IAHS, Wallingford, UK, 93-100, 1990.

Benson, M. A. and Dalrymple, T.: General Field and Office Procedures for Indirect Discharge Measurements, US Governmental Printing Office, Washington, DC, Techniques of WaterResources Investigations, Book 3, 30 pp., 1967.

Bodhaine, G. L.: Measurement of Peak Discharge at Culverts by Indirect Methods, US Governmental Printing Office, Washington, DC, Techniques of Water-Resources Investigations, Book 3, 19 pp., 1968.

Boiten, W.: Hydrometry, A.A. Balkema, Rotterdam, The Netherlands, 246 pp., 2000.

Brumley, B. H., Cabrera, R. G., Deines, K. L., and Terray, E. A.: Performance of a broad-band acoustic Doppler current profiler, IEEE J. Oceanic Eng., 16, 402-407, 1991.

Bureau of Reclamation: Water Measurement Manual, US Government Printing Office, Washington, DC, 317 pp., 1997.

Chen, Y.-C. and Chiu, C.-L.: An efficient method of discharge measurement in tidal streams, J. Hydrol., 265, 212-224, 2002.

Chen, Y.-C. and Chiu, C.-L.: A fast method of flood discharge estimation, Hydrol. Process., 18, 1671-1684, 2004.

Chen, Y.-C., Kuo, J.-T., Yang, H.-C., Yu, S.-R., and Yang, H.-Z.: Discharge measurement during high flow. J. Taiwan Water Conserv., 55, 21-33, 2007 (in Chinese).

Chiu, C.-L.: Entropy and probability concepts in hydraulics, J. Hydraul. Eng.-ASCE, 113, 583-599, 1987.

Chiu, C.-L.: A natural law of open-channel flows, in: Stochastic Hydraulics '96, A. A. Balkema, Rotterdam, The Netherlands, 1527, 1996.

Chiu, C.-L. and Chen, Y.-C.: Efficient methods of measuring discharge and reservoir-sediment flow, in: Risk Analysis in Dam Safety Assessment, Water Resources Publications, LLC, Highlands Rauch, Colorado, 97-116, 1999.

Chiu, C.-L. and Chen, Y.-C.: An efficient method of discharge estimation based on probability concept, J. Hydraul. Res., 41, 589596, 2003.

Chiu, C.-L. and Chiou, J.-D.: Entropy and 2-D velocity distribution in open channels, J. Hydraul. Eng.-ASCE, 114, 738-756, 1988.

Chiu, C.-L. and Said, C. A. A. : Maximum and mean velocities and entropy in open-channel flow, J. Hydraul. Eng.-ASCE, 121, 2635, 1995.

Chow, V. T.: Open-Channel Hydraulics, McGraw-Hill, Singapore, 680 pp. 1973.

Costa, J. E., Cheng, R. T., Haeni, F. P., Melcher, N., Spicer, K. R., Hayes, E., Plant, W., Hayes, K., Teague, C., and Barrick, D.: Use of radars to monitor stream discharge by noncontact methods, Water Resour. Res., 42, W07422, doi:10.1029/2005WR004430, 2006.

Herschy, R. W.: Hydrometry: Principles and Practices, Wiley, West Sussex, England, 376 pp., 1999.

Herschy, R. W.: Streamflow Measurement, Taylor \& Francis, New York, 507 pp., 2009.
Hilgersom, K. P. and Luxemburg, W. M. J.: Technical Note: How image processing facilitates the rising bubble technique for discharge measurement, Hydrol. Earth Syst. Sci., 16, 345-356, doi:10.5194/hess-16-345-2012, 2012.

International Organization for Standardization (ISO): HydrometryMeasuring River Velocity and Discharge with Acoustic Doppler Profilers, ISO, Geneva, Ref. No. ISO 24154, 24 pp., 2005.

International Organization for Standardization (ISO): HydrometryMeasurement of Liquid Flow in Open Channels Using CurrentMeters or fFloats, ISO, Geneva, Ref. No. ISO 748, 46 pp., 2007.

Jarrett, R. D.: Hydraulics of mountain rivers, in: Channel Flow Resistance: Centennial of Manning's Formula, Water Resources Publications, Littleton, Colorado, 287-298, 1992.

Laenen, A.: Acoustic Velocity Meter Systems, US Governmental Printing Office, Washington DC, Techniques of Water-Resources Investigations, 38 pp., 1985.

Le Coz, J., Pierrefeu, G., and Paquier, A.: Evaluation of river discharges monitored by a fixed side-looking Doppler profiler, Water Resour. Res., 44, W00D09, doi:10.1029/2008WR006967, 2008.

Lu, J.-Y., Su, C.-C., and Wang, C.-Y.: Application of a portable measuring system with acoustic Doppler current profiler to discharge observations in steep rivers, Flow Meas. Instrum., 17, 179-192, 2006.

McGuire, K. J., Weiler, M., and McDonnell, J. J.: Integrating tracer experiments with modeling to assess runoff processes and water transit times, Adv. Water Resour., 30, 824-837, 2007.

Moramarco, T., Saltalippi, C., and Singh, V. P.: Estimation of mean velocity in natural channels based on Chiu's velocity distribution equation, J. Hydraul. Eng.-ASCE, 9, 42-50, 2004.

Mueller, D. S., Abad, J. D., García, C. M., Gartner, J. W., García, M. H., and Oberg, K. A.: Errors in acoustic Doppler profiler velocity measurements caused by flow disturbance, J. Hydraul. Eng.ASCE, 133, 1411-1420, 2007.

Nihei, Y. and Kimizu, A.: A new monitoring system for river discharge with horizontal acoustic Doppler current profiler measurements and river flow simulation, Water Resour. Res., 44, W00D20, doi:10.1029/2008WR006970, 2008.

Oberg, K. A. and Mueller, D. S.: Recent applications of acoustic Doppler current profilers, in: Fundamentals and Advancements in Hydraulic Measurements and Experimentation, ASCE, Reston, VA, 341-350, 1994.

O'Connor, J. E. and Webb, R. H.: Hydraulic modeling for paleoflood analysis, in: Flood Geomorphology, John Wiley \& Sons, New York, 393-402, 1988.

Rantz, S. E.: Measurement and Computation of Streamflow: Volume 1. Measurement of Stage and Discharge, US Governmental Printing Office, Washington DC, Water-Supply Paper 2175, 284 pp., 1982.

Viviroli, D. and Weingartner, R.: The hydrological significance of mountains: from regional to global scale, Hydrol. Earth Syst. Sci., 8, 1017-1030, doi:10.5194/hess-8-1017-2004, 2004.

World Meteorological Organization (WMO): Technical Regulations: Volume III, Hydrology, WMO, Geneva, No. 49, 112 pp., 2006. 